\title{
CONSUMO, COMPORTAMENTO INGESTIVO, DESEMPENHO, CARACTERÍSTICAS DE CARCAÇA E RENDIMENTO DE CORTES COMERCIAIS DE CORDEIROS EM TERMINAÇÃO ALIMENTADOS COM FENO OU SILAGEM DE GLIRICÍDIA
}

(Consumption, ingestive behavior, performance, carcar characteristics and yield of commercial cuts of ending lambs fed with hay or gliricide silage)

Antonio José Lemos ${ }^{1}$, Jucileia Aparecida da Silva Morais ${ }^{2}$, Samuel Figueiredo de Souza ${ }^{3}$, Vinicius Silva Oliveira ${ }^{4}$, Ana Carla Santana Andrade ${ }^{5}$, Ana Carolina Pinho dos Santos ${ }^{1}$

\footnotetext{
${ }^{1}$ Serviço Nacional de Aprendiagem Rural - Sergipe, Brasil, ${ }^{2}$ Departamento de Zootecnia, Universidade Federal Rural de Sergipe, Brasil ${ }^{3}$ Embrapa Tabuleiros Costeiros, Aracajú, Sergie, Brasil, ${ }^{4}$ Universidade Federal da Bahía, Salvador, Bahía, Brasil ${ }^{5}$ Universidade Federal Rural de Sergipe, Sergipe, Brasil
}

Corresponding author: lemoszootecnista@hotmail.com

RESUMO: Objetivou-se de avaliar a substituição parcial $\left(574 \mathrm{~g}^{\mathrm{kg}}{ }^{-1}\right)$ do farelo de soja por feno ou silagem de Gliricidia sepium sobre o desempenho, comportamento ingestivo e características de carcaça de cordeiros em terminação. Foram utilizados 18 cordeiros $1 / 2$ Dorper $\times 1 / 2$ Santa Inês, inteiros, com aproximadamente 120 dias de idade, peso corporal médio inicial de $21 \pm 2.2 \mathrm{~kg}$, confinados, em um delineamento experimental inteiramente casualizado, com três tratamentos e seis repetições. Os ingredientes utilizados nas dietas experimentais foram feno de capim elefante (Pennisetum purpureum), farelo de soja, milho moído, feno e silagem de Gliricídia. Os tratamentos foram constituídos da dieta controle $=100 \%$ de farelo de soja; dieta composta por feno de Gliricídia $=426 \mathrm{~g} \cdot \mathrm{kg}^{-1}$ de farelo de soja e $574 \mathrm{~g} \cdot \mathrm{kg}^{-1}$ de feno de Gliricídia; e dieta composta por silagem de Gliricídia $=426 \mathrm{~g} \cdot \mathrm{kg}^{-1}$ de farelo de soja e 574 g. $\mathrm{kg}^{-1}$ silagem de Gliricídia. Os animais alimentados com feno de Gliricídia em substituição parcial ao farelo de soja, obtiveram maiores $(P<0,05)$ consumos de matéria seca, proteína bruta, fibra em detergente neutro e nutrientes digestíveis totais. O consumo de água foi maior no tratamento de feno de Gliricídia. Observou-se maior $(\mathrm{P}<0,05)$ ganho médio diário, peso corporal ao abate, peso de carcaça quente e peso de carcaça fria para os tratamentos contendo feno e silagem de Gliricídia. A substituição parcial do farelo de soja por feno ou silagem de Gliricídia e indicada para ser utilizada na dieta de cordeiros em terminação, por proporcionar maior desempenho e peso de carcaça nos animais. Contudo, a silagem de Gliricídia demonstra maior potencial para ser utilizada na dieta de cordeiros em terminação, sobretudo em regiões semiáridas por reduzir o consumo de água dos animais.

Palavras-chave: Farelo de soja; Ganho de peso; Leguminosa.

ABSTRACT: The objective of this study was to evaluate the partial replacement (574 g.kg-1) of soybean meal with hay or Gliricidia sepium silage on performance, ingestive behavior and carcass characteristics of finishing lambs. Eighteen $1 / 2$ Dorper $\times 1 / 2$ Santa Inês lambs were used, whole, approximately 120 days old, initial average live weight of $21 \pm 2.2 \mathrm{~kg}$, confined, in a completely randomized experimental design, with three treatments and six repetitions. The ingredients used in the experimental diets were elephant grass hay (Pennisetum purpureum), soybean 
meal, ground corn, hay and Gliricidia silage. The treatments consisted of the control diet $=100 \%$ soybean meal; diet consisting of Gliricidia hay $=426$ g.kg-1 of soybean meal and $574 \mathrm{~g} . \mathrm{kg}-1$ of Gliricidia hay; and diet composed of Gliricidia silage $=426$ g.kg-1 of soybean meal and 574 g.kg-1 Gliricidia silage. The animals fed with Gliricidia hay in partial replacement to soybean meal, obtained higher $(P<0.05)$ consumption of dry matter, crude protein, neutral detergent fiber and total digestible nutrients. Water consumption was higher in the treatment of Gliricidia hay. Higher ( $P$ $<0.05)$ average daily gain, live slaughter weight, hot carcass weight and cold carcass weight were observed for treatments containing hay and Gliricidia silage. The partial substitution of soybean meal by hay or Gliricidia silage is indicated to be used in the diet of finishing lambs, as it provides greater performance and carcass weight in the animals. However, Gliricidia silage shows greater potential to be used in the diet of finishing lambs, especially in semi-arid regions as it reduces the animals' water consumption.

Keywords: Soy bran; Weight gain; Legume. 


\section{INTRODUÇÃO}

A busca por alternativas alimentares que visem a redução do custo com a alimentação do rebanho e ao mesmo tempo a obtenção de bons índices produtivos, vem recebendo atenção especial de produtores e pesquisadores (Gonzaga Neto et al., 2015).

Os alimentos proteicos de origem vegetal, como o farelo de soja, apresentam preços mais elevados, contribuindo para o aumento dos custos de produção (Souza et al., 2010). A utilização de fontes proteicas em substituição ao farelo de soja pode ser uma estratégia viável para a redução dos custos com alimentação na ovinocultura, desde que sejam alternativas eficientes, seguras e econômicas, permitindo desempenhos produtivos similares aos animais alimentados com esse ingrediente (Pina et al., 2006).

A Gliricidia sepium, leguminosa arbórea de porte médio, nativa do México, distribuída da América central e norte da América do Sul, apresenta-se como fonte proteica com potencial para ser utilizada na dieta de ruminantes. Essa forrageira apresenta rápido crescimento, é de fácil estabelecimento, possui alta resistência a seca, se adaptando bem a regiões onde há déficit hídrico e uma elevada produção de massa verde/ha/ano (Rangel et al., 2011).

A Gliricídia se destaca pelo elevado teor proteico possuindo aproximadamente $211.8{\mathrm{~g} . \mathrm{kg}^{-1}}^{-1}$ de PB na matéria seca (Silva et al., 2015; Bayão et al., 2016; Castro Filho et al., 2016; Carvalho et al., 2017), possuindo potencial para uso na alimentação animal, possibilitando a obtenção de desempenho produtivo satisfatório (Eniorolunda et al., 2008; Costa et al., 2009; Archimède et al., 2010). Essa forrageira pode ser utilizada como banco de proteína, pastejo direto, consorciado com outras forrageiras ou conservadas na forma de feno ou silagem (Silva, 2009).

Apesar da utilização da Gliricídia está bastante difundida, ainda não há informações suficientes para se estabelecer a melhor forma de conservação dessa forrageira, se na forma de feno ou silagem, e sobre os efeitos na produção de cordeiros utilizando a Gliricídia na forma de feno ou silagem.

Com base no exposto acima este trabalho foi conduzido para testar a hipótese de que a Gliricidia sepium pode ser utilizada na terminação de cordeiros substituindo parcialmente o farelo de soja na forma de feno e silagem. O objetivo do presente trabalho é determinar a melhor forma de conservação da Gliricidia sepium, para ser utilizada na terminação de cordeiros, com base no consumo, comportamento ingestivo, desempenho produtivo, características de carcaça e rendimento de cortes comerciais dos animais.

\section{MATERIAL E MÉTODOS}

O experimento foi desenvolvido, no período de fevereiro a julho de 2014, nas dependências do Instituto Federal de Sergipe (IFS), localizado no município de São Cristóvão, região Leste do Estado de Sergipe. O município apresenta um clima caracterizado por elevadas temperaturas e umidade, com precipitações pluviométricas em torno de $1331 \mathrm{~mm}$ anuais, sendo o período mais chuvoso de março a agosto e temperatura média anual de $25.2^{\circ} \mathrm{C}$.

Foram utilizados 18 cordeiros mestiços ( $1 / 2$ Dorper $\times 1 / 2$ Santa Inês), machos não castrados, com idade média de 120 dias e peso corporal (PC) médio inicial de $21.3 \pm 2.2 \mathrm{~kg}$. Previamente ao início do período experimental, os cordeiros foram pesados, vacinados contra clostridioses, vermifulgados para controle de parasitos internos com medicamento à base de 
albendazole, identificados com colar e alocados em baias individuais por 15 dias, sendo alimentados com uma mistura de feno e silagem de Gliricídia para adaptação a Gliricídia. Posteriormente, os cordeiros foram distribuídos aleatoriamente nos tratamentos e confinados em baias individuais com área de $2.1 \mathrm{~m}^{2}$, com piso de cimento forrado com areia, com acesso a comedouros, bebedouros e saleiros individuais.

O período experimental teve duração de 75 dias, sendo 15 dias de adaptação dos animais às baias, ao manejo e alimentação e 60 dias de confinamento experimental.

delineamento experimental utilizado foi o inteiramente casualizado, com três tratamentos e seis repetições, sendo cada cordeiro uma unidade experimental.

Foram avaliadas três dietas das quais duas consistiram da substituição de 574 g. $\mathrm{kg}^{-1}$ do farelo de soja por feno ou silagem de Gliricídia, sendo que, no tratamento controle, utilizou-se somente farelo de soja como fonte proteica. Sendo assim, os tratamentos testados foram: Controle - dieta formulada a base de farelo de soja, milho moído e feno de capim elefante; Feno de Gliricídia - dieta formulada substituindo 574 g. $\mathrm{kg}^{-1}$ do farelo de soja por feno de Gliricidia sepium; Silagem de Gliricídia dieta formulada substituindo $574{\mathrm{~g} . \mathrm{kg}^{-1}}^{-1}$ do farelo de soja por silagem de Gliricídia sepium.

As dietas foram formuladas para serem isonitrogenadas, com $160 \mathrm{~g} . \mathrm{kg}^{-1}$ de proteína bruta e balanceadas de acordo com o NRC (2007) para ganho de peso de $200 \mathrm{~g}$ animal.dia ${ }^{-1}$ e ingestão de matéria seca estimada em $3.5 \%$ em relação ao PC. A relação volumoso:concentrado utilizada foi de $55: 45$, respectivamente. Os animais tiveram acesso irrestrito a mistura mineral específica para a espécie e categoria (Níveis de garantia da mistura mineral por kg: Cálcio 220 g, Fósforo
$130 \mathrm{~g}$, Magnésio $25.5 \mathrm{~g}$, Enxofre $24 \mathrm{~g}$, Ferro 3000 mg, Manganês 1500 mg, Zinco 4000 mg, Cobre 1200 mg, Cobalto $280 \mathrm{mg}$, lodo $260 \mathrm{mg}$, Selênio $30 \mathrm{mg} \mathrm{e}$ Flúor $300 \mathrm{mg}$ ).

Foram realizadas coletas semanais e diárias dos ingredientes que compunham as dietas e das sobras, respectivamente, obtendo-se amostras compostas que foram identificadas $e$ armazenadas em freezer a $-20^{\circ} \mathrm{C}$. Ao término do período de coletas, as amostras foram descongeladas, présecas em estufa com ventilação forçada a $55^{\circ} \mathrm{C}$ por 72 horas e moídas em moinho de facas do tipo Willey, utilizando peneira com crivo de $1 \mathrm{~mm}$ de diâmetro, para posteriores análises.

As amostras dos ingredientes da dieta e sobras foram analisadas quanto aos teores de matéria seca (MS método 967.03), matéria mineral (MM método 942.05), proteína bruta (PB método 920.29), extrato etéreo (EE método 981.10) (AOAC, 1990). Os teores de fibra em detergente neutro (FDN) e fibra em detergente ácido (FDA) utilizou-se a metodologia adaptada por Deschamps (1999) com modificações relacionadas aos sacos, uma vez que foram utilizados sacos de TNT (tecido-não-tecido) gramatura $100 \mathrm{~mm}$. Os teores de proteína indigestível em detergente neutro (PIDN) e proteína indigestível em detergente ácido (PIDA) foram obtidos de acordo com metodologia descrita por Licitra et al. (1996).

O valor de nutrientes digestíveis totais (NDT) foram calculados segundo Cappelle et al. (2001) pela seguinte equação para os volumosos: NDT = $83.79-0.4171 \times$ FDN e a estimativa do NDT dos concentrados segundo Paterson et al. (2000) pela seguinte equação: NDT $=[88.9-(0.779 \times$ $\%$ FDA)].

Na Tabela 1, estão apresentados os dados da composição química dos ingredientes utilizados nas dietas experimentais. $\mathrm{Na}$ Tabela 2, estão apresentadas as proporções dos 
ingredientes e a composição química das dietas experimentais.

O capim elefante e a Gliricídia utilizados na confecção do feno e da silagem foram obtidos de uma área irrigada em uma propriedade particular denominada fazenda São Pedro das Quebradas, localizada no povoado Canaã, situado no município de
Salgado. $O$ município de Salgado encontra-se na região centro sul do estado de Sergipe, o município apresenta uma altitude média de $102 \mathrm{~m}$, com precipitação média anual de $1.248,6 \mathrm{~mm}$ concentrada entre os meses de Março e Julho e temperatura média anual de $24,6^{\circ} \mathrm{C}$.

Tabela 1. Composição química dos ingredientes utilizados nas dietas experimentais.

\begin{tabular}{|c|c|c|c|c|c|}
\hline Itens & $\begin{array}{c}\text { Feno de capim } \\
\text { elefante }\end{array}$ & $\begin{array}{l}\text { Silagem de } \\
\text { Gliricídia }\end{array}$ & $\begin{array}{l}\text { Feno de } \\
\text { Gliricídia }\end{array}$ & $\begin{array}{l}\text { Farelo } \\
\text { de soja }\end{array}$ & $\begin{array}{l}\text { Milho } \\
\text { moído }\end{array}$ \\
\hline $\begin{array}{l}\text { Matéria seca }\left(\mathrm{g} \cdot \mathrm{kg}^{-1}\right) \\
\mathrm{g} \cdot \mathrm{kg}^{-1} \mathrm{MS}\end{array}$ & 864 & 247 & 824 & 854 & 864 \\
\hline Matéria Orgânica & 935 & 931 & 935 & 932 & 791 \\
\hline Proteína Bruta & 59,2 & 192 & 186 & 478 & 69,1 \\
\hline Extrato etéreo & 12,6 & 24,8 & 22,7 & 22,1 & 47,9 \\
\hline Matéria mineral & 64,9 & 69,0 & 65,4 & 68,3 & 208 \\
\hline $\begin{array}{l}\text { Fibra em Detergente } \\
\text { Neutro }\end{array}$ & 803 & 609 & 640 & 198 & 292 \\
\hline $\begin{array}{l}\text { Fibra em Detergente } \\
\text { Ácido }\end{array}$ & 495 & 430 & 435 & 77,7 & 64,8 \\
\hline $\begin{array}{l}\text { Nutrientes Digestíveis } \\
\text { Totais }\end{array}$ & 503 & 584 & 571 & 828 & 838 \\
\hline $\begin{array}{l}\text { Proteína insolúvel em } \\
\text { detergente neutro }\end{array}$ & 20,5 & 43,4 & 58,6 & 12,4 & 6,10 \\
\hline $\begin{array}{l}\text { Proteína insolúvel em } \\
\text { detergente ácido }\end{array}$ & 11,0 & 20,3 & 29,0 & 1,00 & 0,50 \\
\hline $\mathrm{pH}$ & - & 4,39 & - & - & - \\
\hline N- Amoniacal & - & 2,07 & - & - & - \\
\hline Tanino total & - & 34,9 & 14,1 & - & - \\
\hline
\end{tabular}

Tabela 2. Proporção dos ingredientes e composição química das dietas experimentais

\begin{tabular}{lccc}
\hline & \multicolumn{3}{c}{ Dietas } \\
\hline Itens $\left(\mathrm{g} \cdot \mathrm{kg}^{-1}\right)$ & Controle & $\begin{array}{c}\text { Feno de } \\
\text { Gliricídia }\end{array}$ & Silagem de Gliricídia \\
\hline Feno de capim elefante & 550 & 100 & 100 \\
Feno de Gliricídia & - & 450 & - \\
Silagem de Gliricídia & - & - & 450 \\
Farelo de soja & 235 & 100 & 100 \\
Farelo de milho & 215 & 350 & 350 \\
Itens (g.kg-1) & & & 590 \\
Matéria seca & 869 & 851 & 883 \\
Matéria orgânica & 903 & 884 & 166 \\
Proteína bruta & 160 & 164 & 477 \\
Fibra em detergente neutro & 552 & 491 & 274 \\
Fibra em detergente ácido & 305 & 276 & 689 \\
Nutrientes digestíveis totais & 652 & 684 & \\
\hline
\end{tabular}

A ceifa do capim elefante foi realizada a altura média de $5 \mathrm{~cm}$ do solo quando a planta apresentava aproximadamente 95 dias de idade. Em seguida, o capim colhido foi picado em máquina forrageira, espalhado sobre lonas de polietileno a pleno sol para desidratação, com revolvimento a cada 30 minutos. O ensacamento do feno foi realizado no fim da tarde do terceiro dia 
após o corte, utilizando-se sacos de nylon que ficaram empilhados sobre estrados em galpão.

A Gliricídia utilizada para produzir o feno e a silagem foram semeadas em sacos plásticos para mudas, contendo como substrato uma mistura $2 \times 1$ de terra e esterco de ovinos respectivamente, e posteriormente enviveiradas. Após dois meses de enviveiramento e apresentando altura média de $20 \mathrm{~cm}$, as mudas foram transplantadas para um piquete de 0,6 hectares, dotado de covas previamente abertas, em espaçamento de plantio 1,0 $\times 1,0 \mathrm{~m}$. O feno e a silagem de Gliricídia foram obtidos após 12 meses de plantio, através do corte e seleção de ramos tenros ( $8 \mathrm{~mm}$ de espessura) com folhas do extrato arbóreo.

A forragem destinada ao processo de fenação foi triturada em maquina forrageira, e espalhada sobre uma lona plástica estendida ao sol, revolvendo o material a cada 30 minutos. Após três dias, o feno foi recolhido e ensacado. $\mathrm{O}$ processo de ensilagem ocorreu após a forragem ser triturada, e acondicionada em tonéis com capacidade para 200 litros, sendo 0 processo de compactação para retirada do oxigênio realizado através de pisoteio, com posterior fechamento hermético por período mínimo de 30 dias para ocorrência dos processos fermentativos, segundo metodologia adaptada de Rangel et al. (2011). Tanto o capim elefante quanto a Gliricídia foram picadas em maquina forrageira, o que resulta em tamanho de partículas que variam entre 2 e $5 \mathrm{~cm}$.

A dieta total foi ofertada em duas porções diária, às 08:00h e às 14:00h, procedendo-se à pesagem do alimento fornecido e das sobras para estimativa do consumo diário individual, uma vez ao dia, antes da refeição matinal. A quantidade fornecida foi ajustada a cada três dias, considerando $15 \%$ de sobras.
O consumo de água de cada animal foi determinado pesando-se a quantidade ofertada $\left(\mathrm{kg} \cdot \mathrm{dia}^{-1}\right)$ e sua sobra após 24 horas, por todo o período experimental, sendo calculado por meio da diferença de peso dos baldes antes e após o consumo pelos animais, descontando-se as perdas evaporativas pela diferença após 24 horas. Para quantificar as perdas por evaporação foram dispostos dois baldes em diferentes pontos do galpão e pesados diariamente.

Ao trigésimo dia do experimento foram realizadas as observações do comportamento ingestivo por três dias consecutivos. Para registrar o tempo despendido em ingestão, ruminação e ócio, adotou-se a observação visual dos animais a cada cinco minutos, segundo metodologia descrita por Johnson e Combs (1991), feita por observadores previamente treinados, em sistema de revezamento e posicionados estrategicamente de modo a não incomodar os animais. As observações foram iniciadas às 08:00 horas da manhã com término no mesmo horário do dia seguinte. No mesmo dia, foi realizada a contagem do número de mastigações merícicas (número de bolo) e do tempo despendido para ruminação de cada bolo (segundo por bolo) utilizando-se um cronômetro digital. Para maior acurácia na obtenção dos dados, a contagem das mastigações foi realizada por dois membros fixos da equipe de observadores, o primeiro realizava a contagem das mastigações, enquanto $o$ segundo de posse do cronômetro registrava o tempo de cada ruminação. Para a obtenção das médias das mastigações e do tempo, foram feitas as observações de quatro bolos ruminais em períodos diferentes do dia (9:00 às 11:00 horas; $15: 00$ às $17: 00$ horas; $20: 00$ às 22:00 horas). Foram computados o tempo e o número de mastigações para cada bolo ruminal por animal 
Consumo, comportamento ingestivo, desempenho, características de carcaça e rendimento de

Para obtenção do número de bolos diários procedeu-se à divisão do tempo total de ruminação pelo tempo médio gasto na ruminação de cada bolo, descrito anteriormente.

As variáveis observadas foram: tempo de alimentação, tempo de ruminação e tempo de ócio. Com base nos dados de comportamento e consumo de MS e FDN, foram calculadas as eficiências da alimentação (EFA) e ruminação (EFR), segundo Burger et al. (2000), utilizando-se as seguintes equações:

$\mathrm{EFA}=$ consumo de $\mathrm{MS}\left(\mathrm{kg} \cdot \mathrm{dia}^{-1}\right) /$ tempo de alimentação (h);

EFA = consumo de FDN $\left(\mathrm{kg} \cdot \mathrm{dia}^{-1}\right) /$ tempo de alimentação $(\mathrm{h})$

$\mathrm{EFR}=$ consumo de MS $\left(\mathrm{kg} \cdot \mathrm{dia}^{-1}\right) /$ tempo de ruminação $(\mathrm{h})$;

EFR = consumo de FDN (kg.dia $\left.{ }^{-1}\right) /$ tempo de ruminação $(h)$.

O tempo de mastigação total, o número de bolos ruminais por dia e o número de mastigações merícicas por dia, foram obtidas conforme metodologia descrita por Polli et al. (1996) e Bürger et al. (2000). Durante a coleta de dados na observação noturna dos animais, o ambiente foi mantido com iluminação artificial, sob auxílio de lâmpadas fluorescentes tubulares.

As amostras de silagens foram analisadas quanto ao $\mathrm{pH}$, conforme metodologia descrita em Silva e Queiroz (2002) e nitrogênio amoniacal de acordo com a metodologia descrita por Tosi et al. (1999). Amostras parcialmente secas de feno e silagem de Gliricídia foram acondicionadas em sacos de ziplock e enviadas ao laboratório de nutrição animal da Universidade Federal de Alagoas para quantificar o teor de tanino das amostras segundo metodologia adaptada de Terril et al. (1992).

Para avaliação dos parâmetros de desempenho produtivo, foram realizadas pesagens a cada 15 dias, obedecendo a um jejum de sólidos de 12 horas. As variáveis de desempenho foram: consumo médio diário de matéria seca (CMS), consumo de proteína bruta (CPB), consumo de fibra em detergente neutro (CFDN), Consumo de fibra em detergente ácido (CFDA), consumo de nutrientes digestivos totais (CNDT), ganho de peso médio diário (GMD) e eficiência alimentar (EA = GMD/CMS).

Os animais foram abatidos ao $76^{\circ}$ dia de confinamento, após serem submetidos a um jejum de sólidos por 12 horas e pesados para determinação do peso corporal ao abate (PCA). Posteriormente, foram insensibilizados com a utilização de uma pistola de dardo cativo, suspensos pelas patas traseiras e seguindo-se a secção das artérias carótidas e veia jugular. Após a sangria e esfola, foram retirados 0 conteúdo gastrintestinal, as vísceras, a pele, a cabeça, as patas e os órgãos genitais. Posteriormente procedeu-se a pesagem para obtenção do peso da carcaça quente (PCQ), em seguida as carcaças foram transportadas para câmara frigorífica a $4^{\circ} \mathrm{C}$, onde permaneceram pendurados pelos tendões da perna em ganchos de metal por um período de 24 horas, ao final do qual, foram pesadas para a obtenção do peso de carcaça fria (PCF). Em seguida, foram determinados os rendimentos de carcaça quente $(\mathrm{RCQ}=(\mathrm{PCQ} / \mathrm{PVA}) \times$ 100) $e$ de carcaça fria (RCF = $(P C F / P V A) \times 100)$, segundo as técnicas descritas por Osório et al. (1998). O peso de corpo vazio (PCV $=$ peso corporal - conteúdo gastrintestinal) e o rendimento verdadeiro (RV = $(\mathrm{PCQ} / \mathrm{PCV}) \times 100)$ foram determinadas segundo Osório et al. (2014).

Após a determinação do peso de carcaça fria procedeu-se a separação da carcaça em duas metades, mediante corte sagital da coluna vertebral com auxílio de serra elétrica, na metade direita da carcaça foi realizado um corte transversal entre a $12^{a}$ e $13^{a}$ costelas, 
materializando-se a secção transversal do músculo Longissimus dorsi e com auxíliode paquímetro digital foram mensuradas a espessura de gordura subcutânea (Osório et al., 2014), foi aferido $\mathrm{o} \mathrm{pH}$ com auxílio de pHmetro digital (HACCP- HI 99163) logo após o abate e $24 \mathrm{~h}$ e a temperatura $24 \mathrm{~h}$ após o abate do músculo Longissimus dorsi. A meia carcaça direita foi seccionada em cinco partes, perna, paleta, lombo, costela e pescoço, essas partes foram pesadas e foi calculado o rendimento percentual desses cortes em relação a meia carcaça.

O modelo estatístico utilizado foi: $Y_{i j}=\mu+T_{i}+E_{i j}$; em que: $Y_{i j}=$ valor observado; $\mu=$ média geral; $T_{i}=$ efeito do feno ou silagem de Gliricídia, e $E_{i j}=$ efeito do erro experimental nas parcelas. Os dados obtidos foram submetidos à análise de variância pelo comando PROC GLM do pacote estatístico do SAS (SAS University Edition) e as médias comparadas pelo teste de Tukey, sendo considerado como diferença quando $\mathrm{P}<0,05$.

\section{RESULTADOS}

Observou-se diferença $(P<0,01)$ para os consumos de MS, PB, FDN, FDA, NDT e água em kg.dia ${ }^{-1}$ (Tabela
3). Os animais alimentados com o feno de Gliricídia apresentaram o maior consumo de nutrientes que os demais, e os tratamentos controle e de silagem de Gliricídia não diferiram entre si, exceto para os consumos de NDT e água. Sendo que, os animais alimentados com a silagem da Gliricídia tiveram maior consumo de NDT e menor consumo de água que os animais recebendo a dieta controle.

Para o consumo de nutrientes (MS, PB, FDN, FDA e NDT) em percentual do peso corporal, foi observada diferença $(P<0,01)$ entre os tratamentos (Tabela 3). Os animais alimentados com feno de Gliricídia tiveram maior consumo percentual dos nutrientes, sendo que, os animais alimentados com silagem de Gliricídia apresentaram menor consumo em percentual do peso corporal de FDN e NDT que os animais alimentados com a dieta controle, sendo que, não houve diferença entre ambos os tratamentos para o consumo em porcentagem do peso corporal dos demais nutrientes (MS, PB e FDA).

Não foi observada diferença para os tempos destinados as atividades de ingestão, ruminação, ócio e tempo total de mastigação $(P=0,29 ; P=0,65 ; P=0,89$ e $\mathrm{P}=0,98$; respectivamente) entre os tratamentos (Tabela 4).

Tabela 3 - Consumo médio de nutrientes e de água de cordeiros alimentados com feno ou silagem de Gliricídia em substituição parcial ao farelo de soja.

\begin{tabular}{|c|c|c|c|c|c|}
\hline & \multicolumn{3}{|c|}{ Dietas } & \multirow[b]{2}{*}{ EPM $^{1}$} & \multirow{2}{*}{$\begin{array}{c}\text { Valores } \\
\text { de } \mathrm{P}^{2}\end{array}$} \\
\hline & Controle & $\begin{array}{l}\text { Feno de } \\
\text { Gliricídia }\end{array}$ & $\begin{array}{c}\text { Silagem de } \\
\text { Gliricídia }\end{array}$ & & \\
\hline \multicolumn{6}{|l|}{ Consumo (kg.dia ${ }^{-1}$ ) } \\
\hline Matéria seca & $0,75 b$ & $1,13 a$ & $0,77 \mathrm{~b}$ & 0,06 & $<0,01$ \\
\hline Proteína bruta & $0,12 b$ & $0,19 a$ & $0,13 b$ & 0,01 & $<0,01$ \\
\hline Fibra em detergente neutro & $0,37 b$ & $0,55 a$ & $0,33 b$ & 0,03 & $<0,01$ \\
\hline Fibra em detergente ácido & $0,13 b$ & $0,30 a$ & $0,17 b$ & 0,02 & $<0,01$ \\
\hline Nutrientes digestíveis totais & $0,38 \mathrm{c}$ & $0,75 a$ & $0,56 b$ & 0,04 & $<0,01$ \\
\hline Água & $1,86 b$ & $2,25 a$ & $1,43 c$ & 0,02 & $<0,01$ \\
\hline \multicolumn{6}{|l|}{ Consumo $\left(\% \mathrm{PC}^{3}\right)$} \\
\hline Matéria seca & $3,04 b$ & $3,85 a$ & $2,76 b$ & 0,04 & $<0,01$ \\
\hline Proteína bruta & $0,48 b$ & $0,65 a$ & $0,46 b$ & 0,03 & $<0,01$ \\
\hline Fibra em detergente neutro & $1,51 b$ & $1,86 a$ & $1,19 \mathrm{c}$ & 0,05 & $<0,01$ \\
\hline Fibra em detergente ácido & $0,49 b$ & $0,91 a$ & $0,56 \mathrm{~b}$ & 0,02 & $<0,01$ \\
\hline Nutrientes digestíveis totais & $1,86 \mathrm{~b}$ & $2,25 a$ & $1,43 \mathrm{c}$ & 0,06 & $<0,01$ \\
\hline
\end{tabular}


Observou-se diferença $(P<0,01)$ para as eficiências de alimentação e ruminação, tanto em g de MS quanto de FDN, entre os três tratamentos (Tabela 4). Sendo que, os animais alimentados com feno de Gliricídia tiveram maior eficiência tanto de alimentação quanto de ruminação (de MS e FDN), que os animais alimentados com a dieta controle e com a silagem de Gliricídia, os quais não diferiram entre si.

Tabela 4. Parâmetros do comportamento ingestivo de cordeiros alimentados com dietas contendo feno ou silagem de Gliricídia em substituição parcial ao farelo soja.

\begin{tabular}{|c|c|c|c|c|c|}
\hline \multirow[b]{2}{*}{ Itens } & \multicolumn{3}{|c|}{ Dietas } & \multirow[b]{2}{*}{ EPM $^{1}$} & \multirow{2}{*}{$\begin{array}{l}\text { Valores } \\
\text { de } \mathrm{P}^{2}\end{array}$} \\
\hline & Controle & $\begin{array}{l}\text { Feno de } \\
\text { Gliricídia }\end{array}$ & $\begin{array}{l}\text { Silagem de } \\
\text { Gliricídia }\end{array}$ & & \\
\hline Ingestão (min) & 353 & 318 & 308 & 0,66 & 0,29 \\
\hline Ruminação (min) & 430 & 444 & 461 & 0,79 & 0,65 \\
\hline Ócio (min) & 657 & 678 & 671 & 0,51 & 0,89 \\
\hline Mastigação total (min) & 762 & 760 & 767 & 0,78 & 0,98 \\
\hline \multicolumn{6}{|l|}{ Eficiência } \\
\hline Alimentação (g MS.h ${ }^{-1}$ ) & $230 \mathrm{~b}$ & $576 a$ & $353 b$ & 0,54 & $<0,01$ \\
\hline Ruminação (g MS.h $h^{-1}$ ) & $188 \mathrm{~b}$ & $413 a$ & $236 b$ & 0,97 & $<0,01$ \\
\hline Ruminação (g FDN. ${ }^{-1}$ ) & $63,0 \mathrm{~b}$ & $200 a$ & $104 \mathrm{~b}$ & 0,43 & $<0,01$ \\
\hline \multicolumn{6}{|l|}{ Mastigação merícicas } \\
\hline $\mathrm{N}^{0} \cdot \mathrm{dia}^{-1}$ & $35,577 b$ & $42,340 a b$ & $45,543 a$ & 1,10 & $<0,01$ \\
\hline $\mathrm{N}^{0} \cdot$ bolo $^{-1}$ & $80,5 a$ & $83,8 a$ & $68,6 b$ & 0,89 & $<0,01$ \\
\hline Bolos ruminados $\left(\mathrm{n}^{0} \cdot \mathrm{dia}^{-1}\right)$ & $443 b$ & $511 b$ & $665^{a}$ & 1,13 & $<0,01$ \\
\hline $\begin{array}{l}\text { Tempo de mastigações.bolo }{ }^{-1} \\
\text { (seg.) }\end{array}$ & $56,0 a$ & $52,5 a$ & $41,6 b$ & 0,02 & $<0,01$ \\
\hline
\end{tabular}

Os cordeiros alimentados com a silagem de Gliricídia tiveram maior $(P<0,01)$ número de mastigações merícicas por dia $\left(\mathrm{n}^{\circ} \cdot \mathrm{dia}^{-1}\right)$, que os animais recebendo a dieta controle, sendo que ambos não diferiram dos cordeiros alimentados com o feno de Gliricídia (Tabela 4). Os cordeiros alimentados com a silagem de Gliricídia ruminaram maior número de bolos por dia $(P<0,01)$, que os animais alimentados com a dieta controle e o feno de Gliricídia (Tabela 4). O número de mastigações merícicas por bolo e o tempo de mastigação por bolo (segundos) foram maiores $(P<0,01$, para ambos) para os cordeiros submetidos ao tratamento controle e com feno de Gliricídia.

Os animais do presente trabalho deram preferência a realizarem a atividade de alimentação durante 0 período diurno, das 08:00 às 14:00 (Figura 1).

A atividade de ruminação ocorreu preferencialmente nos períodos noturnos, horário em que a temperatura é mais amena, correspondendo a $81,7 \%$ da ruminação, nos períodos das 20 às 08 horas (Figura 2).

Não foi observada diferença $(P=0,13)$ para o peso corporal final dos animais (PCF). Observou-se diferença para o ganho de peso total (GPT) e ganho médio diário (GMD), $\mathrm{P}=0,04$ para ambos (Tabela 5). Os animais alimentados com o feno de Gliricídia obtiveram maior GPT que os animais recebendo a dieta controle, sendo que, ambos não diferiram dos animais alimentados com a silagem de Gliricídia. 
Observou-se que o uso da Gliricídia, tanto na forma de feno como de silagem, na dieta de cordeiros em terminação não afetou o rendimento e as características de carcaça dos animais $(P>0,05)$ em comparação os animais alimentados com a dieta controle (Tabela 5).

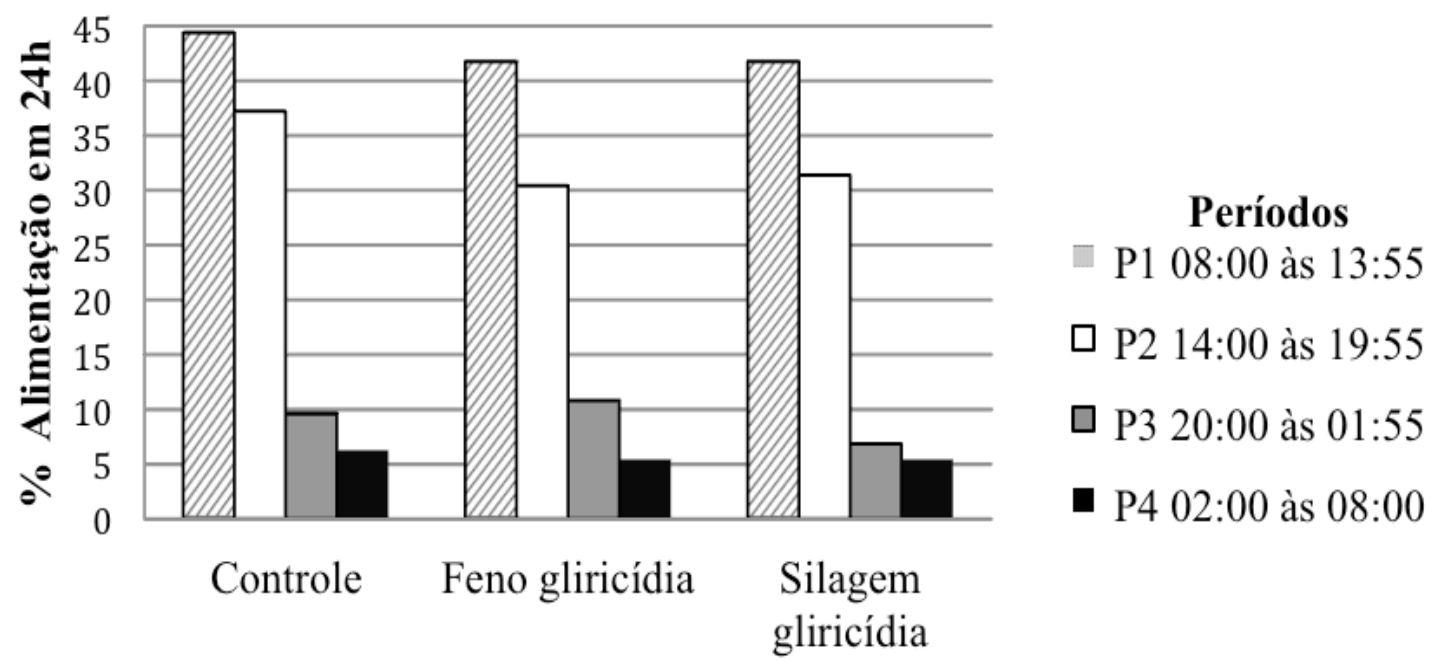

\section{Tratamentos}

Figura 1. Distribuição do tempo despendido em alimentação (\%), em quatro períodos, nas 24 horas do dia.

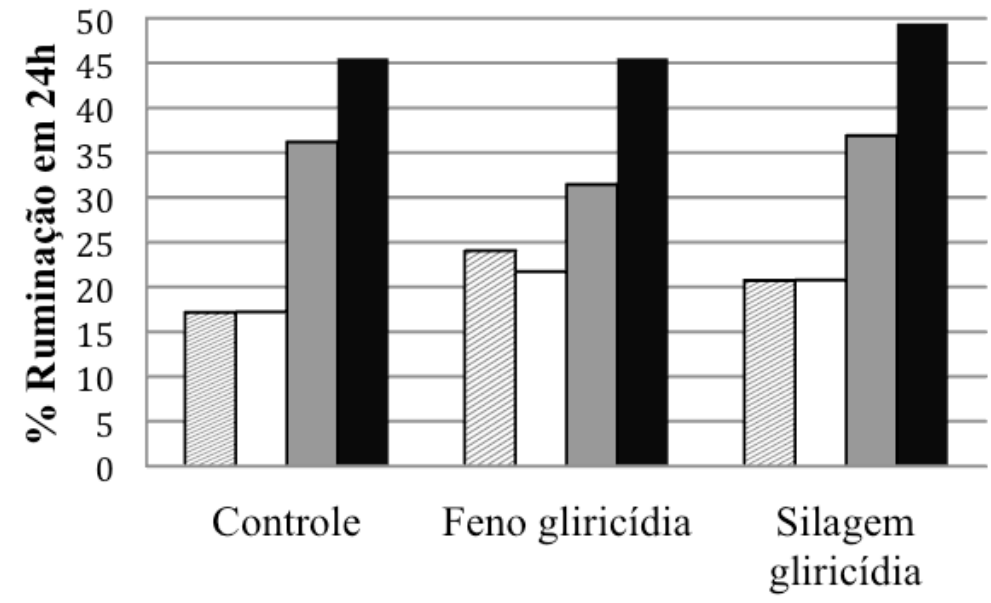

\section{Períodos}

$\square$ P1 08:00 às 13:55

口 P2 14:00 às 19:55

口P3 20:00 às 01:55

P4 02:00 às 08:00

\section{Tratamentos}

Figura 2. Distribuição do tempo despendido em ruminação (\%), em quatro períodos, nas 24 horas do dia.

Os pesos e rendimentos dos cortes comerciais das carcaças dos cordeiros, não foram influenciados $(P>0,05)$ pela utilização da Gliricídia na dieta dos animais, tanto na forma de feno como na forma de silagem (Tabela 6). 
Tabela 5 - Desempenho e características de carcaça de cordeiros alimentados com feno ou silagem de Gliricídia em substituição parcial ao farelo de soja.

\begin{tabular}{|c|c|c|c|c|c|}
\hline \multirow[b]{2}{*}{ Itens } & \multicolumn{3}{|c|}{ Dietas } & \multirow[b]{2}{*}{ EPM $^{1}$} & \multirow[b]{2}{*}{$\begin{array}{c}\text { Valores } \\
\text { de } P^{2}\end{array}$} \\
\hline & Controle & $\begin{array}{c}\text { Feno } \\
\text { de Gliricídia }\end{array}$ & $\begin{array}{c}\text { Silagem de } \\
\text { Gliricídia }\end{array}$ & & \\
\hline Peso corporal inicial (kg) & 20,9 & 21,9 & 21,0 & - & - \\
\hline Peso corporal final $(\mathrm{kg})$ & 26,5 & 32,8 & 32,3 & 1,04 & 0,13 \\
\hline Ganho de peso total (kg) & $6,11 \mathrm{~b}$ & $11,6 a$ & $9,74 a b$ & 0,94 & 0,04 \\
\hline Ganho médio diário $(\mathrm{kg})$ & $0,09 b$ & $0,18 a$ & $0,17 a$ & 0,01 & 0,04 \\
\hline Eficiência alimentar & 0,16 & 0,15 & 0,15 & 0,01 & 0,08 \\
\hline Peso de corpo vazio $(\mathrm{kg})$ & $20,7 b$ & $26,5 a$ & $25,1 a$ & 0,68 & 0,01 \\
\hline Peso de carcaça quente $(\mathrm{kg})$ & $11,9 b$ & $14,9 a$ & $14,1 \mathrm{a}$ & 0,51 & 0,02 \\
\hline Peso de carcaça fria $(\mathrm{kg})$ & $11,6 b$ & $14,6 a$ & $13,8 a$ & 0,52 & $<0,01$ \\
\hline $\begin{array}{l}\text { Rendimento de carcaça } \\
\text { quente }(\%)\end{array}$ & 46,5 & 47,9 & 47,2 & 0,61 & 0,12 \\
\hline Rendimento carcaça fria (\%) & 45,4 & 47,0 & 46,5 & 0,69 & 0,12 \\
\hline Rendimento verdadeiro (\%) & 57,2 & 56,6 & 56,0 & 0,73 & 0,40 \\
\hline Espessura de gordura (mm) & 1,17 & 1,39 & 1,37 & 0,08 & 0,52 \\
\hline Comprimento interno $(\mathrm{cm})$ & 54,2 & 54,5 & 55,7 & 0,69 & 0,68 \\
\hline $\begin{array}{l}\text { Indice de compacidade de } \\
\text { carcaça }\left(\mathrm{kg} \cdot \mathrm{cm}^{-1}\right)\end{array}$ & 0,22 & 0,27 & 0,24 & 0,01 & 0,10 \\
\hline Perímetro de tórax $(\mathrm{cm})$ & 66,3 & 68,8 & 67,5 & 0,81 & 0,49 \\
\hline Profundidade de tórax $(\mathrm{cm})$ & 18,7 & 20,5 & 18,3 & 0,45 & 0,10 \\
\hline Largura de garupa $(\mathrm{cm})$ & 17,2 & 19,2 & 18,0 & 0,46 & 0,21 \\
\hline Largura de tórax $(\mathrm{cm})$ & 18,0 & 19,7 & 18,7 & 0,61 & 0,50 \\
\hline $\mathrm{pH}$ Oh & 6,7 & 6,7 & 6,3 & 0,08 & 0,08 \\
\hline $\mathrm{pH} 24 \mathrm{~h}$ & 5,7 & 5,5 & 5,7 & 0,49 & 0,57 \\
\hline Temperatura $\left({ }^{\circ} \mathrm{C}\right) \mathrm{Oh}$ & 30,4 & 29,5 & 30,7 & 0,06 & 0,54 \\
\hline Temperatura $\left({ }^{\circ} \mathrm{C}\right) 24 \mathrm{~h}$ & 10,6 & 10,5 & 11,0 & 1,08 & 0,98 \\
\hline
\end{tabular}

Erro padrão da média; ${ }^{2}$ Probabilidade da significância. Médias seguidas de letras distintas na mesma linha diferem estatisticamente entre si pelo teste de Tukey.

Tabela 6. Pesos e rendimentos de cortes comercias da carcaça de cordeiros alimentados com feno ou silagem de Gliricídia em substituição parcial ao farelo de soja.

\begin{tabular}{|c|c|c|c|c|c|}
\hline & \multicolumn{3}{|c|}{ Dietas } & \multirow[b]{2}{*}{ EPM $^{1}$} & \multirow[b]{2}{*}{ Valores de $\mathrm{P}^{2}$} \\
\hline & Controle & $\begin{array}{l}\text { Feno de } \\
\text { Gliricídia }\end{array}$ & $\begin{array}{c}\text { Silagem de } \\
\text { Gliricídia }\end{array}$ & & \\
\hline \multicolumn{6}{|l|}{$\mathrm{Kg}$} \\
\hline Perna & 2,11 & 2,69 & 2,25 & 0,10 & 0,04 \\
\hline Paleta & 1,13 & 1,36 & 1,26 & 0,05 & 0,21 \\
\hline Lombo & 0,42 & 0,42 & 0,47 & 0,03 & 0,79 \\
\hline Costela & 1,58 & 1,89 & 1,60 & 0,10 & 0,36 \\
\hline Pescoço & 0,53 & 0,61 & 0,59 & 0,04 & 0,74 \\
\hline \multicolumn{6}{|l|}{$\%$} \\
\hline Perna & 36,9 & 38,6 & 36,7 & 0,87 & 0,64 \\
\hline Paleta & 19,6 & 19,5 & 20,4 & 0,26 & 0,35 \\
\hline Lombo & 7,35 & 5,84 & 7,75 & 0,48 & 0,25 \\
\hline Costela & 27,2 & 27,2 & 25,7 & 0,98 & 0,79 \\
\hline Pescoço & 8,97 & 8,82 & 9,51 & 0,52 & 0,87 \\
\hline
\end{tabular}




\section{DISCUSSÃO}

O menor consumo de MS observado nos animais alimentados com a silagem de Gliricídia (Tabela 3), pode ter ocorrido devido a maior presença de taninos na silagem em comparação com o feno, conforme observado na Tabela 1. Além disso, forrageiras conservadas na forma de silagem são consumidas em menor quantidade do que na forma verde ou feno, devido a presença de compostos pouco palatáveis na silagem, como aminas e ácidos provenientes da fermentação (Baumont et al., 2000) e/ou a produção excessiva de metabólitos produzidos durante a digestão (Dulphy e Demarquilly, 1994). O aumento do consumo de MS leva ao aumento do consumo das frações que compõe a dieta como PB, FDN, FDA e NDT, por essa razão os animais alimentados com o feno de Gliricídia tiveram maior consumo dessas frações (Tabela 3).

Além dos fatores discutidos acima, vale ressaltar que o consumo de MS é determinante no desempenho animal, pois é através dele que o animal obtém os nutrientes necessários para atender suas necessidades de mantença e produção (Gonzaga Neto et al., 2015). Sendo que, o consumo de PB e NDT exercem papel fundamental no desempenho animal (Detmann et al., 2014; Silva et al., 2016), pois limitações na disponibilidade de proteína e energia no rúmen compromete o desenvolvimento da microbiota ruminal (Leng, 1990), o que resulta no menor desempenho animal.

O fato dos animais alimentados com a silagem de Gliricídia obterem maior ganho de peso total (GPT) e maior ganho médio diário (GMD), do que os animais recebendo a dieta controle (Tabela 5). Ocorreu devido ao maior consumo de MS (kg.dia $\left.{ }^{-1}\right)$ e PB e NDT principalmente (Tabela 3), como discutido anteriormente. Além de que, os cordeiros alimentados com a silagem de Gliricídia obtiveram maior consumo de MS e das frações (PB, FDN, FDA e NDT) em percentual do peso corporal. Sendo que, o consumo de MS em $\%$ do PC foi de $3,85 \%$, ficando acima do preconizado pela formulação da dieta $(3,5 \%)$ para um ganho de 200 g.dia ${ }^{-1}$. Além disso, vale ressaltar que o ganho médio diário dos animais alimentados com feno e silagem de Gliricídia, 0,18 e $0,19 \mathrm{~kg}_{\mathrm{dia}}{ }^{-1}$, respectivamente, ficaram mais próximos do preconizado com a formulação da dieta $\left(0,2 \mathrm{~kg} \cdot \mathrm{dia}^{-1}\right)$, segundo NRC (2007). Sendo que, os animais alimentados com a dieta controle tiveram um ganho médio diário $\left(0,11 \mathrm{~kg} \cdot \mathrm{dia}^{-1}\right)$ muito abaixo do estimado.

De acordo com o NRC (2007), ovinos com peso corporal médio de 20 $\mathrm{kg}$, para obterem um ganho médio diário de $200 \mathrm{~g}$, necessitam consumir 116 g.dia ${ }^{-1}$ de PB e 610 g.dia ${ }^{-1}$ de NDT. Sendo assim, apenas os cordeiros alimentados com o feno de Gliricídia obtiveram o consumo de PB e NDT acima do recomendado (119 e 750 g.dia ${ }^{-1}$ respectivamente), conforme observado na Tabela 3 , já os animais recebendo a dieta controle obtiveram consumo de PB e NDT abaixo do recomendado (112 e 380 g. $\mathrm{kg}^{-1}$, respectivamente), explicando o menor desempenho dos animais alimentados com a dieta controle.

O menor consumo de água observado nos cordeiros que consumiram silagem de Gliricídia em relação aos demais tratamentos pode ser explicado pelo alto teor de umidade da dieta $(40,96 \%)$ o que possibilitou ao animal suprir parte da sua demanda por água e diminuir a procura para consumo da mesma. Os resultados do presente trabalho, estão em consonância com os relatados por Souza et al. (2010), que encontraram maior consumo voluntário de água, para ovinos que consumiram feno de maniçoba (Manihot epruinosa Pax e Hoffmann) em comparação a 

cortes comerciais de cordeiros em terminação alimentados com feno ou silagem de gliricídia

animas que consumiram silagem. $O$ consumo de alimentos suculentos, com maior teor de umidade, reduz a ingestão de água (Santana Neto et al., 2015).

A maior eficiência de alimentação e ruminação, tanto em $\mathrm{g} \cdot \mathrm{kg}^{-1}$ de $\mathrm{MS}$ como em g. $\mathrm{kg}^{-1}$ de FDN, observada nos animais alimentados com o feno de Gliricídia (Tabela 4), ocorreu devido ao maior consumo de MS que os cordeiros desse tratamento apresentaram, em comparação aos demais tratamentos (Tabela 3). Além disso, a dieta contendo o feno de Gliricídia possuía $61,0 \mathrm{~g}_{\mathrm{kg}}{ }^{-1}$ a menos de FDN que a dieta controle, sendo que, quando comparado a dieta contendo silagem de Gliricídia o teor de FDN é apenas 14,0 g. $\mathrm{kg}^{-1}$ menor. O aumento no teor de FDN estimula a atividade de ruminação (Oh et al., 2016) e consequentemente reduz a eficiência de alimentação e ruminação, devido a menor taxa de passagem da fibra (Huhtanen et al., 2016) e ao efeito de repleção ruminal que a fibra possui (Silva et al., 2018).

O menor teor de MS observado na dieta contendo a silagem de Gliricídia (Tabela 2), pode ter influenciado no maior número de bolos ruminados (número.dia ${ }^{-1}$ ) e no maior número de mastigações merícicas (número.dia ${ }^{-1}$ ). Visto que, o volume de alimento ofertado no cocho dos cordeiros alimentados com a silagem de Gliricídia, foi $45 \%$ maior que os demais, por conta do menor teor de MS. O fato dos cordeiros recebendo a dieta controle e com feno de Gliricídia terem apresentado maiores número de mastigações merícicas por bolo e o tempo de mastigação por bolo (segundos), conforme visto na Tabela 4. Pode ter ocorrido devido ao maior teor de matéria seca presente nas dietas controle e feno de Gliricídia, o que exige maior tempo de manipulação e mastigação, para hidratar e reduzir o tamanho das partículas do bolo alimentar nos animais que consomem feno do que naqueles que consumem silagem.

O fato dos cordeiros terem exercido a atividade de consumo preferencialmente durante o dia e a de ruminação preferencialmente no período noturno (Gráficos 1 e 2, respectivamente), é explicado pelo manejo de fornecimento de ração, pois as dietas foram ofertadas durante 0 período diurno as 8 e $14 \mathrm{~h}$. Além de que, segundo Miranda et al. (1999) os animais concentram a atividade de ingestão de alimentos durante o período diurno.

O fato das dietas contendo tanto a silagem como o feno de Gliricídia não terem influenciado o peso corporal final dos animais (Tabela 5), demonstra que a Gliricídia possui potencial para ser utilizada na dieta de ovinos em terminação em substituição parcial ao farelo de soja. Além de que, nos tratamentos contendo o feno e a silagem da Gliricídia o peso corporal ao abate dos animais, a espessura de gordura a proporção de músculo atendem a exigência de mercado (Gois et al., 2018).

Dentre os componentes do peso corporal a carcaça é o que possui maior importância (Osório et al., 1996), pois é esse componente que determinará o valor comercial do animal (Hopkins, 1992). Nesse sentido, os tratamentos contendo o feno e a silagem de Gliricídia se destacaram, visto que, em ambos os animais apresentaram maior peso de carcaça, tanto quente quanto fria (Tabela 5), apesar do rendimento não ter sido influenciado pelos tratamentos. Esses resultados podem ser explicados devido ao maior ganho de peso total e ganho médio diário, que os animais recebendo o feno e a silagem de Gliricídia obtiveram.

$O$ fato das dietas contendo feno e silagem de Gliricídia não afetarem as características de carcaça (Tabela 5), assim como o rendimento de cortes 
comerciais, comprovam que esses ingredientes possuem potencial para serem utilizados na dieta de cordeiros em terminação, substituindo parcialmente o farelo de soja. $\dot{E}$ importante salientar ainda que a utilização da Gliricídia, tanto na forma de feno como de silagem, contribui para diminuir a dependência dos produtores por insumos proteicos externos, pois, a Gliricídia pode ser produzida e explorada na própria propriedade para fornecimento aos animais. Esse fato também foi constatado por Hao e Ledin (2001), que trabalhando com níveis de inclusão de Gliricídia (folhas e galhos tenros) como fonte proteica na dieta de caprinos, reduziram a quantidade de concentrados proteicos utilizados sem que ocorressem decréscimos no ganho de peso dos animais.

Do mesmo modo, é pertinente ressaltar o impacto do emprego da Gliricídia independente da forma utilizada na alimentação de cordeiros, sendo que, no presente trabalho, a Gliricídia serviu não apenas como substituto a fonte proteica, mas, também, como fonte de volumoso. Atributo relevante, tendo em vista a baixa qualidade dos volumosos, quase sempre presente nas formulações de dietas em regiões semiáridas.

\section{CONCLUSÕES}

É recomendado o emprego de feno e silagem de Gliricídia como fonte proteica e de volumoso na formulação de dietas para cordeiros em terminação. Sendo que, o fornecimento de Gliricídia na forma de silagem reduz o consumo de água, esta torna-se uma excelente alternativa na dieta de cordeiros, sobretudo em regiões semiáridas.

\section{REFERÊNCIAS}

Association of Official Analytical Chemists. Official methods of analysis. $15^{\text {th }}$ ed. Association of Official Analytical Chemist. Arlington, VA, USA; 1990.

ARCHIMĖDE, H.; GONZÁLES-GARCÍA, $E$; DESPOIS, P.; et al. Substitution of corn and soybean with green banana fruits and Gliricidia sepium forage in sheep fed hay-based diets: effects on intake, digestion and growth. Journal of Animal Physiology and Animal Nutrition, v. 94, n. 1, p. 118-128, 2010.

BAUMONT, R.; PRACHE, S.; MEURET, $M$. et al. How forage characteristics influence behaviour and intake in small ruminants: a review. Livestock Production Science, v. 64, n. 1, p. 1528, 2000.

BAYÃO, G.F.V.; EDVAN, R.L.; CARNEIRO, M.S.S. et al. Dehydration and chemical composition of Leucena ("Leucena leucocephala") and Gliricidia ("Gliricidia sepium"). Revista Brasileira de Saúde e Produção Animal, v. 17, n. 3, p. 365-373, 2016.

BÜRGER, P.J.; PEREIRA, J.C.; QUEIROZ, A.C. et al. Comportamento ingestivo em bezerros holandeses alimentados com dietas contendo diferentes níveis de concentrado. Revista Brasileira de Zootecnia, v. 29, n. 1, p. 236-242, 2000.

CAPPELLE, E.R.; VALADARES FILHO, S.C.; SILVA, J.F.C. et al. Estimativas do valor energético a partir de características químicas e bromatológicas dos alimentos. Revista Brasileira de Zootecnia, v. 30, n. 6, p. 1837-1856, 2001.

CARVALHO, C.B.M.; SILVA, S.F.; CARNEIRO, M.S.S. et al. Chemical composition of silage and hay "Gliricidia sepium" in different residue heights. Revista Brasileira de Saude e Producao Animal, v. 18, n. 2, p. 239248, 2017.

CASTRO FILHO, E.S.; MUNIZ, E.N.; RANGEL, J.H.A. et al. Dry matter yield 
Consumo, comportamento ingestivo, desempenho, características de carcaça e rendimento de cortes comerciais de cordeiros em terminação alimentados com feno ou silagem de gliricídia

and bromatological composition of gliricidia in different crop densities. Ciência Rural, v. 46, n. 6, p. 10381043, 2016.

COSTA, B.M.C.V.; SANTOS, I.C.V.; OLIVIERA, G.J.C. et al. Avaliação de folhas de gliricidia sepium (jacq.) walp por ovinos. Archivos de Zootecnia, v. 58, n. 221, p. 33-41, 2009.

DESCHAMPS, F.C. Implicações do período de crescimento na composição química e digestão dos tecidos de cultivares de capim elefante (Pennisetum purpureum Schumach). Revista Brasileira de Zootecnia, v. 28, n. 6, p. 1358-1369, 1999.

DETMANN, E.; VALENTE, E.E.L.; BATISTA, E.D. et al. An evaluation of the performance and efficiency of nitrogen utilization in cattle fed tropical grass pastures with supplementation. Livestock Science, v. 162, p. 141-153, 2014.

DULPHY, J.P.; DEMARQUILY, C. The regulation and prediction of feed intake in ruminants in relation to feed characteristics. Livestock Production Science, v. 39, n. 1, p. 1-12, 1994.

ENIOROLUNDA, O.O.; JINADU, O.A.; OGUNGBESAN, M.A. et al. Effect of combined levels of Panicum maximum and Gliricidia sepium on nutrients digestibility and utilization by west African dwarf goats fed cassava offal based concentrate. Research Journal of Animal Science. v. 2, p. 149-153, 2008.

GONZAGA NETO, S.; OLIVEIRA, R.L.; LIMA, F.H.S. et al. Milk production, intake, digestion, blood parameters, and ingestive behavior of cows supplemented with by-products from the biodiesel industry. Tropical Animal Health and Production, v. 47, n. 1, p. 191-200, 2015.

GOIS, G.C.; CAMPOS, F.S.; PESSOA, R.M.S. et al. Qualidade da carne de ovinos de diferentes pesos e condição sexual. Pubvet, v.12, n.5, a97, p.1-9, 2018.

HAO, N.V.; LEDIN I. Performance of growing goats fed Gliricidia maculate. Small Ruminant Research, v. 39, n. 2, p. 113-119, 2001.

HOPKINS, D.L. Estimating carcass weight from live weight in lambs. Small Ruminant Research, v. 6, n. 4, p. 323328, 1991.

HUHTANEN, P.; DETAMANN, E.; KRIZSAN, S.J. Prediction of rumen fiber pool in cattle from dietary, fecal, and animal variables. Journal of dairy science, v. 99, n. 7, p. 5345-5357, 2016.

JOHNSON, T.R.; COMBS, D.K. Effects of prepartum diet, inert rumen bulk, and dietary polythylene glicol on dry matter intake of lactating dairy cows. Journal of Dairy Science, v. 74, n. 3, p. 933944, 1991.

LENG, R.A. Factors affecting the utilization of "poor-quality" forages by ruminants particularly under tropical conditions. Nutrition research reviews, v. 3, n. 1, p. 277-303, 1990.

LICITRA, G.; HERNANDEZ, T.M.; VAN SOEST, P.J. Standardization of producers for nitrogen fractionation of ruminants feeds. Animal feed science and technology, v. 77, n. 1-2, p. 99113, 1999.

MIRANDA, L.F.; QUEIROZ, A.C.; VALADARES FILHO, S.C. et al. Comportamento ingestivo de novilhas leiteiras alimentadas com dietas à base de cana-de-açúcar. Revista Brasileira de Zootecnia, v. 28, n. 3, p. 614-620, 1999.

National Research Council. Nutrientre quirements of small ruminants: sheep, goats, Cervids and new world camelids. $6^{\text {th }}$ rev. ed. Washington DC: National Academy Press. 2007. 
OH, M.R..; HONG, H.; LI, H.L. et al. Effects of Physically Effective Neutral Detergent Fiber Content on Intake, Digestibility, and Chewing Activity in Fattening Heifer Fed Total Mixed Ration. Asian-Australasian journal of animal sciences, v. 29, n. 12, p. 1719, 2016.

OSÓRIO, J.C.S.; AVILA, V.; JARDIM, P.O.C. et al. Produção de carne em cordeiros cruza Hampshire Down com Corriedale. Revista Brasileira Agrociência, v. 2, n. 2, p. 99-104, 1996.

OSÓRIO, J.C.S.; OSÓRIO, M.T.M.; FERNANDES, A.R.M. et al. Técnicas de Avaliação in vivo, na Carcaça e na Carne. $1^{\text {th }}$ ed. São Paulo: Roca, 2014.

OSÓRIO, J.C.S.; OSÓRIO, M.T.M.; JARDIM, P.O. Métodos para avaliação da produção de carne ovina: "in vivo" na carcaça e na carne. Pelotas: UFPEL, 1998.

PATTERSON, T.; KLOPFENSTEIN, T.; MILTON T, et al. Evaluation of the 1996 beef cattle NRC model predictions of intake and gain for calves fed low or medium energy density diets. Nebraska Beef Cattle Reports, v. 73, p. 26-29, 2000.

PINA, D.S.; VALADARES FILHO, S.C.; VALADARES, R.F.D. et al. Consumo e digestibilidade aparente total dos nutrientes, produção e composição do leite de vacas alimentadas com dietas contendo diferentes fontes de proteína. Revista Brasileira de Zootecnia, v. 35, n. 4, p. 1543-1551, 2006.

POLLI, V.A.; RESTLE, J.; SENNA, D.B. et al. Aspectos relativos à ruminação de bovinos e bubalinos em regime de confinamento. Revista Brasileira de Zootecnia, v. 25, n. 5, p. 987-993, 1999.

RANGEL, J.H.A.; MUNIZ, E.M.; SÁ, C.O. et al. Implantação e manejo de legumineira com gliricídia (Gliricidia sepium). Circular Técnica, 2011; 63p.

SANTANA NETO, J.A.; CASTRO FILHO, E.S.; ARAÚJO, H.R. Potencial das cactáceas como alternativa alimentar para ruminantes no semiárido. Nutritime Revista Eletrônica, v. 12, n. 6, p. 4426-4434, 2015.

SILVA, D.J.; QUEIROZ, A.C. Análise de alimentos: métodos químicos e biológicos. $3^{\text {th }}$ ed. Viçosa MG 2002; $253 p$.

SILVA, S. Plantas forrageiras de $\mathbf{A}$ a Z. $1^{\text {th }}$ ed. Viçosa MG 2009; 255p.

SILVA, M.D.A.; CARNEIRO, M.S.S.; PINTO, A.P. et al. Evaluation of the chemical composition of woody forage silages of the Brazilian semiarid. Semina: Ciências Agrárias, v. 36, n. 1, p. 571-578, 2015.

SILVA, L.D.; PEREIRA, O.G.; SILVA, T.C. et al. Effects of silage crop and dietary crude protein levels on digestibility, ruminal fermentation, nitrogen use efficiency, and performance of finishing beef cattle. Animal Feed Science and Technology, v. 220, p. 22-33, 2016.

SOUZA, V.L.; ALMEIDA, R.; SILVA, D.F.F. et al. Substituição parcial de farelo de soja por ureia protegida na produção e composição do leite. Arquivo Brasileiro de Medicina Veterinária e Zootecnia, v. 62, n. 6, p. 1415-1422, 2010.

SILVA, T.E.; DETMANN, E.; PALMA, M.N.N. et al. Desenvolvimento de modelo para predição da fração digestível da fibra em detergente neutro para bovinos em condições tropicais. Revista Brasileira de Biometria, v. 36, n. 2, p. 290-315, 2018.

\section{Statistical Analysis System -} University Edition. Disponível em: http://www.sas.com/pt_br/software/unive rsity-edition.html. Acessado em: 9 de janeiro de 2018.

TERRILL, T.H.; ROWAN, A.M.; DOUGLAS, G.B. et al. Determination of extractable and bound condensed tannins concentrations in forage plants, 
Consumo, comportamento ingestivo, desempenho, características de carcaça e rendimento de 110 cortes comerciais de cordeiros em terminação alimentados com feno ou silagem de gliricídia

protein concentrate meals and cereal grains. Journal of the Science of Food and Agriculture, v. 58, n. 3, p. 321-329, 1992.

TOSI, P.; MATTOS, W.R.S.; TOSI, H. et al. Avaliação do capim elefante (Pennisetum purpureum Schum.) cultivar Taiwan A-148, ensilado com diferentes técnicas de redução de umidade. Revista Brasileira de Zootecnia, v. 28, n. 5, p. 947-954, 1999. 